\title{
A report of two cases of chronic serious manganese poisoning treated with sodium para-aminosalicylic acid
}

\author{
Ky Shuqin, Deng Haishang, Xie Peiyi, Hu Wanda
}

\begin{abstract}
Two cases of chronic manganese poisoning were treated with sodium para-aminosalicylic acid (PAS-Na; $6 \mathrm{~g} /$ day in $500 \mathrm{ml}$ of $10 \%$ glucose solution by intravenous drip). The results indicated that one had been clinically cured and that the other had obviously improved in clinical symptoms and signs. Thus PAS-Na appears to be an effective drug for treatment of serious chronic manganese poisoning.
\end{abstract}

Sodium para-aminosalicylic acid (PAS-Na) is a drug used in the past for treating tuberculosis. Its pharmacology was studied in detail many years ago and the drug was shown to have a wide range of action and slight side effects.

Department of Industrial Hygiene and Occupational Diseases, Guangxi Medical College, Nanning City, Guangxi, People's Republic of China

K Shuqin, X Peiyi, H Wanda

The Workers' Hospital of Wuzhou City, Guangxi, People's Republic of China

D Haishang

Table 1 The symptoms of two chronic serious manganese poisoning cases before and after being treated with $P A S-N a$ and during follow up

\begin{tabular}{|c|c|c|c|c|c|c|}
\hline & \multicolumn{3}{|l|}{ Case 1} & \multicolumn{3}{|l|}{ Case 2} \\
\hline & $\begin{array}{l}\text { Before } \\
\text { treatment }\end{array}$ & $\begin{array}{l}\text { After } \\
\text { treatment }\end{array}$ & Follow up & $\begin{array}{l}\text { Before } \\
\text { treatment }\end{array}$ & $\begin{array}{l}\text { After } \\
\text { treatment }\end{array}$ & Follow up \\
\hline Headache & ++ & - & - & - & - & - \\
\hline Giddiness & ++ & - & - & + & - & - \\
\hline Weariness & + & - & - & ++ & - & - \\
\hline Insomnia & + & - & - & - & - & - \\
\hline Amnesia & ++ & \pm & - & + & \pm & \pm \\
\hline Purposeless weeping and laughing & ++ & $=$ & - & $++t$ & \pm & \pm \\
\hline Speech disorders & ++ & - & - & +++ & $\bar{t}+$ & $\bar{t}+$ \\
\hline Asthenia in all four limbs & + & - & - & $++t$ & + & + \\
\hline Arthralgia & + & - & - & ++ & - & - \\
\hline Myalgia in all four limbs & + & - & - & + & - & \\
\hline Myoclonus in all four limbs & ++ & \pm & \pm & ++ & - & - \\
\hline Numbness in all four limbs & + & $\beth$ & $\beth$ & ++ & - & - \\
\hline Heavy feeling in lower limbs & ++ & - & - & +++ & ++ & + \\
\hline Palpitation & + & - & - & & - & - \\
\hline Salivation & + & - & - & $++t$ & + & + \\
\hline Excessive perspiration & ++ & - & - & - & - & - \\
\hline
\end{tabular}

Our early studies suggest that PAS-Na is an effective drug in treating early manifestations of chronic manganese poisoning and causes increased urinary excretion of manganese. ${ }^{12}$ Recently we applied PAS-Na to treat two cases of serious chronic manganese poisoning.

\section{Case histories}

Case 1 was a 50 year old woman who had been occupationally exposed to manganese for 21 years (1963-84). The range of manganese $\left(\mathrm{MnO}_{2}\right)$ concentration in the air of the workplace was 1.16$31.3 \mathrm{mg} / \mathrm{m}^{3}$.

The patient had suffered from palpitations and hand tremor since 1968 and had been misdiagnosed as having thyroidism. In 1980, she showed symptoms such as headache, giddiness, palpitation, salivation, failing memory, lower limb myalgia, myasthenia, and tetany and numbness in arms and legs. The patient often knelt down suddenly when walking. Physical examination at that time showed hands, tongue, and eyelids to be tremulous, rigidity or hypertonicity of muscles, a positive Houk's sign, and a positive nose pointing test. She had tremor while writing and a 
Table 2 The signs of two chronic serious manganese poisoning cases before and after being treated with $P A S-N a$ and during follow up

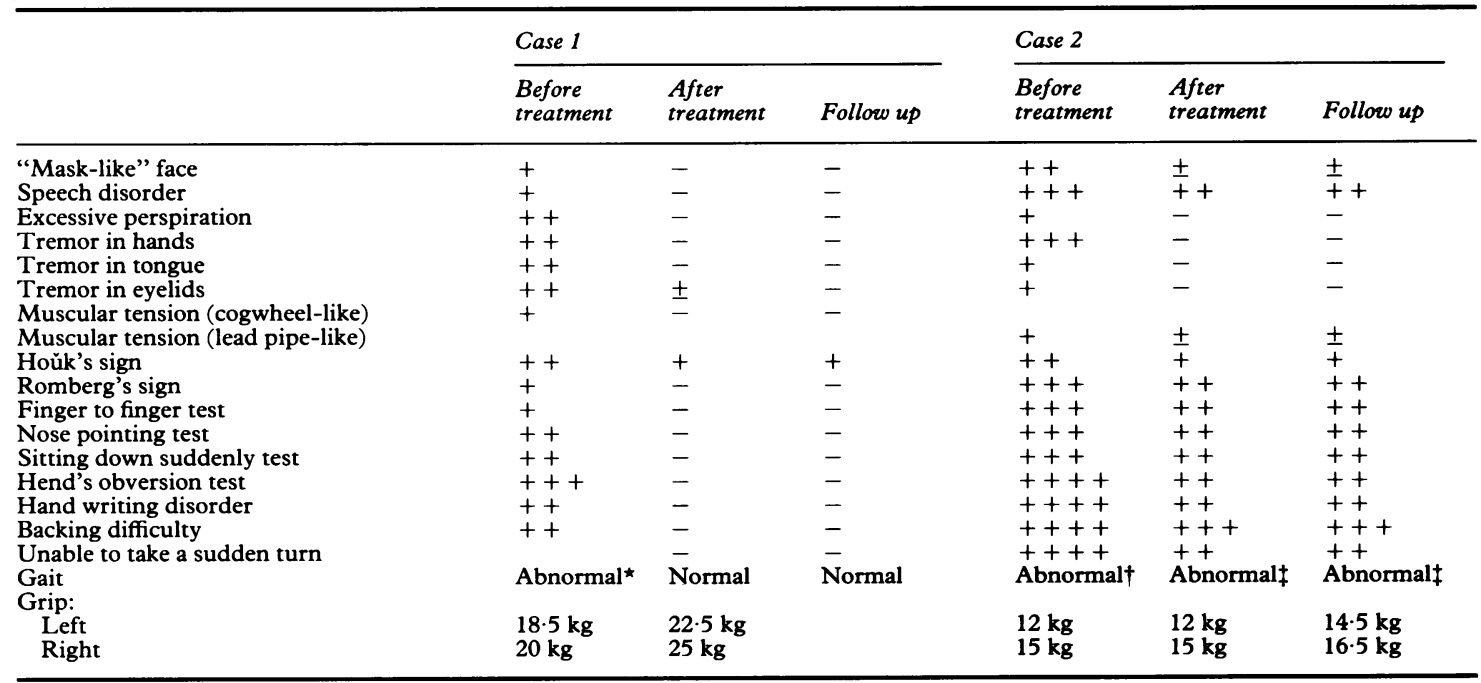

* Feet sliding without lifting the toes.

+ Unable to walk a step.

$\ddagger$ Slow walking without help.

dragging gait. The patient was diagnosed as having chronic mild manganese poisoning by the occupational diseases diagnosis group (ODDG) in 1982 and admitted to hospital at the end of the year. After treatment with $\mathrm{CaNa}_{2}$ EDTA for expelling manganese over two courses, the symptoms were improved. These symptoms, however, returned and intensified in the first half of 1983. The patient had tingling in the muscles of extremities and aesthenia. Sometimes there was cramp in the limbs and pronounced trembling all over. She often went to the outpatient department of the hospital and was treated with Artane tablets, L-dopa, calcium gluconate, and several kinds of vitamins for a prolonged period. All the symptoms became worse. After admission to hospital for the second time in November 1984, her clinical symptoms and signs improved slightly and she was discharged after having taken $\mathrm{CaNa}_{2}$ EDTA for two courses combined with treatment with Ldopa and Artane tablets, energy mixture, and various vitamins. Six months later, however, the symptoms and signs emerged again and, became more aggravated daily. The patient had such symptoms as a tic at the angle of the lips and a bitten tongue while speaking, the upper extremities trembled greatly while writing and carrying. The body was unsteady when walking, and she had difficulty in coping with routine life. She was diagnosed as having chronic serious manganese poisoning by ODDG and was admitted to hospital for the third time in March 1987.

Tables 1 and 2 show the symptoms and signs found on examination at admission. The pulse was $80 / \mathrm{min}$, blood presure was $120 / 80 \mathrm{~mm} \mathrm{Hg}$, and body weight was $48 \cdot 5 \mathrm{~kg}$. Her lips often twitched. Handwriting became characteristically irregular with small letters (see fig 1). Abnormal signs in heart, lungs, and abdomen were not found by physical examination. Chest $x$ ray film showed that lung markings had increased slightly. The electrocardiogram showed occasional premature ventricular beats. Electroencephalogram was normal. Laboratory tests showed normal blood, urine, and faeces and normal hepatic and renal function. Urine manganese content was $3 \cdot 11 \mu \mathrm{g} / 24 \mathrm{~h}$. Urine contained 17-hydroxysteroid $(2 \cdot 16 \mathrm{mg} / 24 \mathrm{~h})$ and 17 -ketosteroid $(6 \cdot 7 \mathrm{mg} / 24 \mathrm{~h})$.

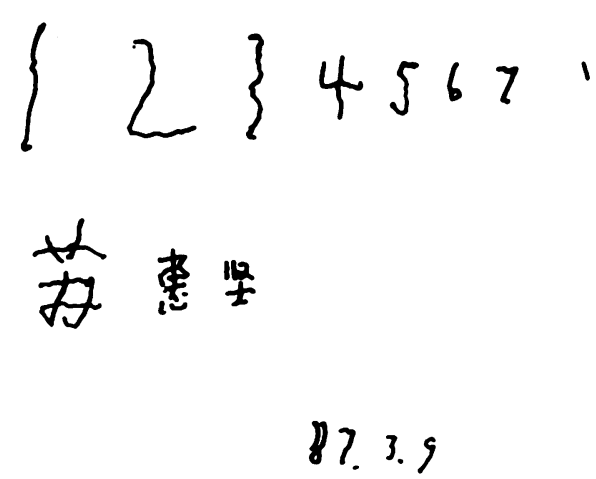

Figure 1 Handwriting of case 1 before treatment. 


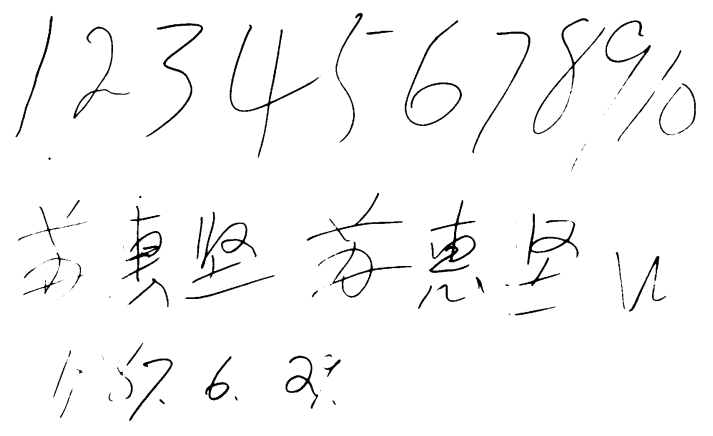

Figure 2 Handwriting of case 1 after three and a half months of treatment.

The patient began treatment with PAS-Na on 11 March 1987. A solution, composed of $500 \mathrm{ml}$ of $10 \%$ glucose and $6 \mathrm{~g}$ of PAS-Na, was given by intravenous drip per day. Each course of treatment included continuously taking medicine for four days and stopping for three days. Having been treated for three and half months, her symptoms and signs almost disappeared. Her morale and mental state were good, her appetite improved, and her ability to cope with daily life and writing ability recovered to normal (see fig 2). Almost no abnormalities in signs were found on auxiliary examination. During the treatment, her urinary manganese concentration was $6.79 \mu \mathrm{g} / 24 \mathrm{~h}$ (mean value). After treatment it was $2 \cdot 8 \mu \mathrm{g} / 24 \mathrm{~h}$. The other laboratory tests showed no abnormalities. She was diagnosed as clinically recovered by ODDG and discharged from hospital.

When she was examined at follow up 19 months later, the symptoms and signs were normal (see tables 1 and 2). The cure was long term.

Case 2 was a 62 year old male worker. $\mathrm{He}$ was engaged in crushing manganese ores from 1958-62.

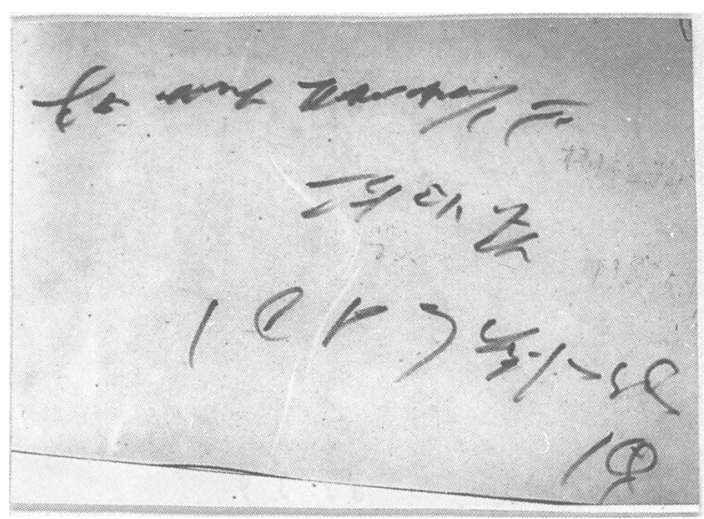

Figure 3 Handwriting of case 2 before treatment.

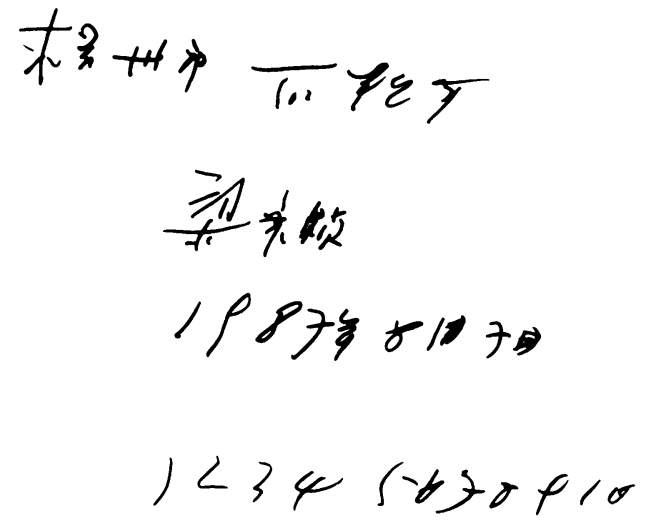

Figure 4 Handwriting of case 2 after three and a half months of treatment.

The manganese $\left(\mathrm{MnO}_{2}\right)$ concentration in the air of his workplace was $25-83.3 \mathrm{mg} / \mathrm{m}^{3}$.

The patient had had difficulty in walking and had been unable to feed himself properly for twenty five years. In 1961, he developed such symptoms as headache, dizziness, palpitations, and excessive salivation. He often exhibited purposeless weeping and laughing, general tiredness, pain and tic in extremities and difficulty in walking uphill.

On physical examination he had difficulty in speaking and tremor in hands, tongue, and eyelids. The muscular hypertonia, nose pointing test, and Romberg's sign were positive. He could not stand on one leg and his gait appeared hurried. The group of neurologists and hygienists diagnosed the patient as having chronic serious manganese poisoning in 1962. He was admitted to hospital but discharged himself voluntarily without any treatment because of fear of injections. The patient had stayed at home since 1963 because of the disease. He had been walking with a crutch since 1979. He felt stiffness of lower extremities, was unsteady when standing, and was unable to walk a step without a crutch by 1982 . The patient was sent to hospital by others who carried him on their backs on 13 May, 1987. Tables 1 and 2 show the symptoms and signs found on the second admission. The pulse was $90 / \mathrm{min}$, blood pressure was $136 /$ $80 \mathrm{~mm} \mathrm{Hg}$, and weight was $42.5 \mathrm{~kg}$. Face muscle and the lip angle had tics. He felt something in his mouth and often chewed on nothing. His mouth leaked food when eating. The spoon splashed its contents when he used it to eat soup. His head was slanting down to the right. He didn't walk without help. He could move, with a slow pace only, with the help of surrounding objects. Taking one step needed one to two minutes, and his gait consisted of lifting heels and dropping toes. Muscles had atrophied over his lower extremities because of disuse. Handwriting 
was difficult, and the words were often illegible (fig 3). Heart, lungs, and abdomen were normal. Chest $x$ ray film showed that lung markings had increased slightly. The electrocardiogram and electroencephalogram were normal. Results of routine examination of blood, urine, and faeces were normal. Liver and renal function were also normal. Biochemical examination of urine disclosed that urinary manganese concentration was $2 \cdot 21 \mu \mathrm{g} / 24 \mathrm{~h}$, 17-hydroxysteroid concentration was $2.6 \mathrm{mg} / 24 \mathrm{~h}$, and 17 -ketosteroid concentration was $10 \cdot 14 \mathrm{mg} / 24 \mathrm{~h}$.

The patient had ingested PAS-Na in tablet form for two weeks from 22 May, 1987, and the treatment had then been modified to $500 \mathrm{ml}$ of $6 \mathrm{~g}$ PAS-Na added to $10 \%$ glucose solution given by intravenous drip. Tables 1 and 2 show the symptoms and signs at re-examination after treatment for three and a half months. He felt more "soft and comfortable." His speaking was clearer than before. His "mask-like" face had eased. He used a spoon well and his mouth no longer leaked food when eating. He walked faster than before, without help (taking one minute 20 seconds to cover $22 \mathrm{~m}$ ) and was able to turn a corner slowly. His handwriting ability was evidently improved (see fig 4). Results of various auxiliary examinations were grossly normal. The concentration of manganese in urine was $7 \cdot 76 \mu \mathrm{g} / 24 \mathrm{~h}$ during the treatment and $3 \cdot 1 \mu \mathrm{g} / 24 \mathrm{~h}$ after treatment. Values from other laboratory tests were not obviously changed. So he was discharged from hospital with evident improvement in his clinical symptoms and signs. Six months later follow up examination showed that the benefits were long term.

\section{Discussion}

Chronic manganese poisoning is regarded as an occupational disease that has no special treatment. It has been reported that metal chelating agents would increase manganese discharge from urine and improve clinical symptoms in some cases. In early cases of chronic manganese poisoning chelating agents were of conflicting benefit but did seem to produce some improvement in the condition if applied in its early phase when presumably neuronal destruction had not yet occurred. No improvement could be expected in those cases who had structural neurological lesions and extrapyramidal signs and symptoms. ${ }^{4}$ Poor results with $\mathrm{CaNa}_{2}$ EDTA in seven cases in the advanced phase but encouraging results only in one patient with early signs and symptoms was also reported. ${ }^{4}$ Treatment with EDTA was successful in two mild cases, but in three cases with more advanced neurological signs there was no improvement. ${ }^{4}$ Also EDTA applied to mild manganese poisoning for three to four treatment courses could improve $60 \%$ of cases, but gave no improvement in serious manganese poisoning with Parkinson's syndrome. ${ }^{3}$ It has been suggested that the late stage of serious managanese poisoning should not be treated with metal chelating agents, but with symptomatic treatment. Some anti-acetylcholine drugs such as Artane, Kémadrine, and Scopolamine are used in symptomatic treatment in most cases. In the past few years, L-dopa and 5-hydroxy tryptophan have been used in chronic manganese poisoning with Parkinson's syndrome. During the course of treatment, the patient's muscular tension disorder was improved or disappeared but the original signs recurred soon after stopping drugs.

Our paper reports the application of PAS-Na in two cases of serious manganese poisoning. Case 1 had typical Parkinson's syndrome. She was admitted to hospital twice and took $\mathrm{CaNa}_{2}$ EDTA to expel manganese, combined with other treatment. The results are similar to other reports. ${ }^{35}$ The patient received only PAS-Na treatment for three and a half months during her last stay in hospital. This time, her clinical symptoms and signs gradually improved and then disappeared. At follow up 19 months later no signs of relapse were found. It is 25 years since case 2 had been diagnosed as having chronic serious manganese poisoning with Parkinson's syndrome. After treatment with PAS-Na for three and a half months, his clinical symptoms and signs were improved.

\section{Conclusion}

Treatment with PAS-Na has been used effectively in the treatment of chronic serious managanese poisoning. But its mechanism is not clear and needs further study.

$1 \mathrm{Ky}$ Shugin, Hu Wanda. Effective observation on treatment of chronic manganese poisoning with sodium para-amino salicylate. Occupational Medicine 1982;4:8.

$2 \mathrm{Li}$ Yantao, Ky Shugin. Clinical evaluation on treatment of the chronic manganese poisoning with para-amino salicylate. Industrial Health and Occupational Diseases 1986;6:363.

3 The anti-epidemic station of Guangzhou City. The prevention and treatment of occupational manganese poisoning. New Medical and Pharmacological Dispatches 1973;1:43.

4 World Health Organisation. Manganese. Environmental health criteria, Geneva: WHO, 1981:76.

$5 \mathrm{Gu}$ Xuegi, Wang Yilan. Labour Health and Occupational Medicine. 1st ed. Beijing: People's Health Publishing House, 1985;54:2.

Accepted 13 May 1991. 